\title{
Hochwasserrisikomanagement - eine immerwährende Aufgabe
}

Ende des Jahres 2015 wurden die Hochwasserrisikomanagementpläne veröffentlicht. Jetzt beginnt die Arbeit - von neuem. Eine Sisyphus-Arbeit? Kommen wir immer wieder zum gleichen Ergebnis: Wir fangen bei null an und schaffen es nicht?

Die griechische Mythologie ist das eine - das Hochwasserrisikomanagement das andere. Gemäß Artikel 14 der Hochwasserrisikomanagement- Richtlinie evaluieren wir die Bewertung des Hochwasserrisikos, der Gefahren- und Risikokarten sowie die Pläne selbst. Aber sind wir da nicht wieder bei Sisyphus? Pläne gab es in der Vergangenheit schon genug: Hochwasserschutzplanungen, Hochwasseraktionspläne und jetzt noch die Hochwasserrisikomanagementpläne. Viele Planungen sind nicht umgesetzt worden, auch weil sie vielleicht gar nicht umsetzbar waren, vielleicht auch weil viele am grünen Tisch erarbeitet und zu wenig mit den Betroffenen geredet wurde.

Selbstkritik ist hier gefragt. Wir haben uns auf dem achten Forum zur Hochwasserrisikomanagement- Richtlinie in Mainz zur Umsetzung dieser Richtlinie mit aktuellen Hochwasserrisikoma- nagementplänen befasst: Was ist gut gelaufen, was ist schlecht gelaufen? Was ist davon in den nächsten sechs Jahren umsetzbar? Spätestens dann, wenn die Zwischenbilanz gezogen wird, werden wir es wissen: Ist der Versuch, den Hochwasserschutz europaweit auf neue Füße zu stellen, gelungen oder bleibt es nur bei weiteren Planungen. In diesem Zusammenhang haben wir uns weiterhin mit Maßnahmen aus der Praxis beschäftigt und last but not least - die wichtige Frage der Finanzierung beleuchtet.

Häufig werden in Grußworten Zitate großer Ökonomen, Politiker oder Wissenschaftler bemüht, um positive Einstellungen zu vermitteln. Ich will diese Zitate durch eine Aussage eines großen Musikers, nämlich des Jazzpianisten und Bigband- Leaders Duke Ellington, erweitern: „Probleme sind Gelegenheiten zu zeigen, was man kann." Das sollten wir auch tun.

In diesem Themenheft sind die wichtigsten Vorträge des achten Forums veröffentlicht, so dass sich auch diejenigen Leser der Fachzeitschrift Wasser- Wirtschaft, die nicht in Mainz dabei sein konnten, ein Bild über den Stand der Diskussionen machen können. 